\title{
El caso "Tres Bocas" y su importancia para la institucionalidad implicada en la gestión del Santuario de la Naturaleza del río Cruces (Corte Suprema)
}

\author{
Comentario de Felipe Guerra Schleef
}

Santiago, diez de diciembre de dos mil catorce.

\section{Vistos:}

En estos autos Rol No 16.706-2014, se ha interpuesto recurso de casación en el fondo por la Superintendencia del Medio Ambiente en contra de la sentencia dictada por el Tercer Tribunal Ambiental con fecha 30 de mayo de este año que acogió la reclamación deducida por Carlos Javier Montoya Villarroel en contra de la Resolución No 98, de 14 de febrero de 2014 de la aludida Superintendencia que requirió el ingreso al Sistema de Evaluación Ambiental del proyecto "Loteo Riberas de La Dehesa".

Se trajeron los autos en relación.

\section{Considerando:}

Primero: Que la recurrente denuncia como vulnerado el artículo 13 de la Ley $\mathrm{N}^{\circ} 19.880$, en relación con el artículo 62 de la Ley Orgánica de la Superintendencia del Medio Ambiente, toda vez que los sentenciadores establecen que el predio Tres Bocas se encuentra dentro del Santuario de la Naturaleza Carlos Anwandter y que se configura la situación de hecho prevista en la letra p) del artículo 10 de la Ley $\mathrm{N}^{\circ} 19.300$, pero sin embargo, decidió anular todo el proceso de fiscalización y la Resolución $\mathrm{N}^{\circ} 98$ que requirió el ingreso al Sistema de Evaluación de Impacto Ambiental del proyecto por la existencia de supuestos vicios, que no tienen el carácter de esencial que exige la ley para que proceda la invalidación del acto.

Cita al efecto los considerandos $64^{\circ}, 65^{\circ}, 75^{\circ}, 76^{\circ}, 87^{\circ}$ y $92^{\circ}$ del fallo recurrido, de los cuales extrae como conclusiones que el fallo recurrido considera que:

a) La Superintendencia del Medio Ambiente debió consultar al Ministerio del Medio Ambiente sobre los límites del Santuario de la Naturaleza.

b) Los Oficios de ese Ministerio contienen imprecisiones legales.

c) La resolución de la Superintendencia no profundiza sobre las premisas que la llevan a concluir que el predio está emplazado en una isla. 
Añade que las omisiones consignadas en las letras a) y c) son los vicios que llevaron a los sentenciadores a dejar sin efecto todo el proceso de fiscalización y la resolución reclamada.

Indica que la Superintendencia ofició al Ministerio, que recibió el Oficio N ${ }^{\circ} 288$ de la Secretaria Regional de este, en el cual se informa que el Consejo de Monumentos Nacionales informará en forma oficial si las obras están dentro del Santuario de la Naturaleza Carlos Anwandter, quién lo hizo en el Oficio No 3347 , en el cual se establece que las intervenciones fiscalizadas se ejecutaron al interior del Santuario, de acuerdo a los límites de este establecidos en el Decreto Supremo No 2734 del Ministerio de Educación del año 1981.

Agrega que el fallo impugnado estimó que estos pronunciamientos contenían imprecisiones legales, estableciendo el considerando sexagésimo quinto del mismo que los artículos 1 y 31 de la Ley No 17.288, en relación con el Decreto Supremo No 2734 ya citado, le entregaban al Ministerio del Medio Ambiente, en acuerdo con el Consejo de Monumentos Nacionales, la facultad de definir si el predio se encontraba dentro o fuera del Santuario, por lo que, las respuestas entregadas a la Superintendencia no pudieron servir de fundamento y motivación fáctica para la dictación del acto administrativo.

Añade que pese a lo anterior, en el considerando nonagésimo segundo los sentenciadores concluyen que el predio Tres Bocas, en el cual se desarrolla el proyecto se encuentra dentro del Santuario.

En cuanto a la falta de fundamento de la conclusión de la recurrente respecto a que el predio se encontraba en una isla, aduce que de existir, ella sería inconsistente, puesto que recae sobre un punto que el propio tribunal considera zanjado, como puede leerse del considerando octogésimo séptimo del fallo recurrido, lo que le quita el carácter de esencial al vicio.

Por último, señala que los sentenciadores contravinieron el artículo 13 de la Ley No 19.880 ya que no solo consideró vicios que no tenían carácter de esenciales, sino que además hizo que tales defectos afectaran etapas y diligencias que les eran totalmente ajenas.

Segundo: Que a juicio de la recurrente si el tribunal no hubiera incurrido en los yerros descritos, no habría invalidado la Resolución $\mathrm{N}^{\circ} 98$ ni el proceso de fiscalización ambiental, razón por la cual concluye que ellos tuvieron una influencia decisiva en lo resuelto.

Tercero: Que para el buen entendimiento de este recurso, se efectuará una breve relación de los antecedentes de autos:

a) La Resolución No 98 de 14 de febrero de 2014 de la Superintendencia del Medio Ambiente, requiere, bajo apercibimiento de sanción a Carlos Montoya, que ingrese al Sistema de Evaluación Ambiental el proyecto Loteo Riberas de La Dehesa, fundándose al efecto en lo establecido en la letra p) del artículo 10 de la Ley $\mathrm{N}^{\circ}$ 19.300, habida consideración que el Decreto Supremo No 2734, del año 1981, del Ministerio de Educación, declara Santuario de la Naturaleza "el lecho, islas y zonas de inundación 
del Río Cruces y Chorocamayo, entre el extremo norte de la Isla Teja por el sur y dos kilómetros al norte del castillo San Luis de Alba por el norte".

b) En el fallo recurrido, en lo que interesa al análisis, se establece que:

- El predio se encuentra situado dentro del Santuario.

- El loteo tiene como finalidad última su urbanización.

- La normativa ambiental vigente faculta solo al Servicio de Evaluación Ambiental para determinar si las actividades ejecutadas dentro de un Santuario de la Naturaleza son o no susceptibles de causar un impacto ambiental, por lo que corresponderá a este organismo determinar el impacto que él tenga sobre el mismo.

Cuarto: Que los vicios que la sentencia atribuye a la Resolución $N^{\circ} 98$ de la Superintendencia consisten en que no se habría solicitado pronunciamiento al Ministerio del Medio Ambiente sobre los límites del Santuario y que ésta no justifica la conclusión relativa a que el predio se encontraba en una isla, por lo que cabe analizar si tales vicios se configuran y en caso positivo, si revisten relevancia, en términos tales que produzcan la nulidad del procedimiento de fiscalización y de la Resolución con que finaliza el mismo.

Quinto: Que en lo que dice relación con la omisión de oficiar al Ministerio antes aludido, el recurrente afirma que en el considerando décimo séptimo del fallo impugnado se consigna que la Superintendencia recibió el Oficio No 288 de la Secretaria Regional del Ministerio, quien en lugar de contestar directamente a lo solicitado por ella expresa que el Consejo de Monumentos Nacionales informará si las obras están en el Santuario de la Naturaleza Carlos Anwandter, entidad que evacuó el informe por Oficio No 3347 , en el que afirma que las intervenciones se ejecutaron al interior del Santuario, considerando al efecto los límites para dicha área protegida establecidos en el Decreto Supremo $\mathrm{N}^{\circ} 2734$.

Sexto: Que interesa definir si la omisión que la sentencia le atribuye a la recurrente constituye el vicio que en concepto de los sentenciadores es causal de la nulidad del procedimiento sancionatorio y de la Resolución reclamada. Para claridad de la decisión, se transcribe a continuación, en lo pertinente, el considerando $64^{\circ}$ del fallo recurrido: "Este Tribunal estima que en virtud de lo establecido en los artículos 1 y 31 de la Ley $\mathrm{N}^{\circ} 17.288$, en relación con el Decreto Supremo No 2.734, de 03 de junio de 1981, del Ministerio de Educación, hoy en día es el Ministerio del Medio Ambiente, en acuerdo con el Consejo de Monumentos Nacionales -el primero en su calidad de custodio, y el segundo como tutor y protector de los Santuarios de la Naturaleza-, el organismo del Estado competente para definir y modificar, mediante acto administrativo, en virtud de lo dispuesto en el artículo 3 de la Ley 19.880, los límites de los Santuarios de la Naturaleza.

Por consiguiente, la SMA, durante el procedimiento de fiscalización, que terminó en la Resolución Recurrida, debió consultar al Ministerio del Medio Ambiente -el que 
debe contar con el acuerdo del Consejo de Monumentos Nacionales- sobre los límites del Santuario, cosa que no ocurrió. La ausencia de este trámite vicia la Resolución Recurrida, por lo que este Tribunal la anulará, por haber sido pasada sin la consulta de rigor a la autoridad competente, única autorizada para definir si el Predio se encontraba o no dentro del Santuario".

Séptimo: Que el artículo 31 de la Ley $\mathrm{N}^{\circ} 17.288$ en sus incisos segundo y tercero, modificados por el artículo cuarto, letras a) y b) de la Ley $\mathrm{N}^{\circ} 20.417$, establece que los santuarios de la naturaleza quedarán bajo la custodia del Ministerio del Medio Ambiente y que no se podrá sin la autorización previa del Servicio iniciar en ellos trabajos de construcción, excavación o cualquiera otra actividad que pudiera alterar su estado natural.

Acorde con lo anterior, el artículo 120 del Decreto Supremo No 40 del año 2013 del Ministerio del Medio Ambiente, Reglamento del Sistema de Evaluación de Impacto Ambiental, establece que el permiso para iniciar los trabajos a que se refiere el artículo treinta y uno inciso tercero de la Ley $\mathrm{N}^{\circ} 17.288$ debe ser otorgado por el Servicio.

La referida autorización antes de la modificación legal citada, era de competencia del Consejo de Monumentos Nacionales.

Por su parte, también la Ley $\mathrm{N}^{\circ} 20.417$ modificó el artículo treinta y cuatro de la Ley $\mathrm{N}^{\circ} 19.300$, estableciendo al efecto que la administración y supervisión del Sistema Nacional de Áreas Silvestres Protegidas del Estado corresponderá al Servicio de Biodiversidad y Áreas Protegidas, disponiéndose en el artículo octavo transitorio que dentro del plazo que venció el 26 de enero de 2011 el Presidente de la República debía enviar al Congreso Nacional el proyecto de ley que crea el Servicio de Biodiversidad y Áreas Protegidas.

Consta de Boletín 9404-12 que en junio de este año ingresó en primer trámite constitucional al Senado el proyecto que crea el referido Servicio, encontrándose a esta fecha en trámite.

En el Mensaje $\mathrm{N}^{\circ} 161-362$ del proyecto se consigna que la Ley $\mathrm{N}^{\circ} 17.288$, sobre Monumentos Nacionales, que estableció las regulaciones para la creación de Santuarios de la Naturaleza, no obstante haber sido modificada el año 2010 por la Ley No 20.417, regula someramente esta figura, dejando vacíos en materias vinculadas con su declaración, administración y protección.

Octavo: Que cabe en este contexto definir si el Servicio a que se refiere el artículo 31 de la ley sobre Monumentos Nacionales es el Consejo de ese organismo, el Ministerio del Medio Ambiente o el Servicio de Biodiversidad y Áreas Protegidas.

Sobre esta materia, se ha acompañado a estos autos el Dictamen $N^{\circ} 26.190$ de 7 de julio de 2012 de la Contraloría General de la República, que efectuando una interpretación de las normas precedentemente citadas, concluye que el Servicio mencionado en el artículo 31 de la Ley $N^{\circ} 17.288$, no es el Consejo de Monumentos Nacionales ni tampoco el Ministerio de Medio Ambiente, sino que el Servicio de Biodiversidad y Áreas Protegidas, criterio que es compartido por estos sentenciadores. 
No es el Consejo de Monumentos Nacionales, pues la Ley N²0.417 sustituyó en el inciso tercero del artículo 31 de la Ley N N $^{0}$ 17.288, la palabra "Consejo" por "Servicio", modificación que carecería de todo sentido si la intención del legislador hubiera sido que el Consejo siguiera otorgando las autorizaciones.

Tampoco puede ser el Ministerio de Medio Ambiente por cuanto, si esa hubiere sido la intención del legislador, lo habría mencionado como Ministerio, como lo hace en el inciso segundo del mismo artículo 31, agrega el Dictamen citado, invocando al efecto el artículo 22 de la Ley $\mathrm{N}^{\circ} 18.575$, en cuanto dispone que los ministerios son órganos administrativos de ejecución en los casos calificados que ordena la ley, lo cual no ocurre en este caso.

La conclusión entonces que el "Servicio" a que se refiere el inciso tercero del artículo 31 de la ley de Monumentos Nacionales es el Servicio de Biodiversidad y Áreas Protegidas, se sustenta en lo dispuesto en los artículos 34 de la Ley $\mathrm{N}^{\circ}$ 19.300, 31 de la Ley $\mathrm{N}^{\circ} 17.288$ y $4^{\circ}$ y $8^{\circ}$ transitorio de la Ley $\mathrm{N}^{\circ} 20.417$, de los cuales se colige que ese Servicio es tanto el administrador del denominado Sistema Nacional de Áreas Silvestres Protegidas del Estado como el supervisor de las áreas silvestres protegidas de propiedad privada, entre estas, los santuarios de la naturaleza.

Ahora bien, la circunstancia que no se haya creado hasta la fecha el Servicio referido, no significa que la función que a este le competería no deba ser ejercida por otro órgano de la administración, toda vez, que como bien se reseña en el Dictamen ya citado de la Contraloría General de la República, conforme a lo establecido en los artículos 3 y 28 de la Ley $\mathrm{N}^{\circ} 18.575$, de acuerdo al principio de continuidad de la función pública, "en virtud del cual los órganos de la administración tienen por finalidad promover el bien común atendiendo las necesidades públicas en forma continua y permanente" la potestad de autorizar las obras que se realizan en el santuario de la naturaleza se encuentra radicada en el Consejo de Monumentos Nacionales.

Noveno: Que definido lo anterior, es del caso analizar lo sostenido en el considerando $64^{\circ}$ del fallo recurrido, cuyo tenor, en lo pertinente, establece que es el Ministerio del Medio Ambiente, en su calidad de custodio, el organismo del Estado competente para definir y modificar mediante acto administrativo, en virtud de lo dispuesto en el artículo $3^{\circ}$ de la Ley $\mathrm{N}^{\circ} 19.880$, los límites de los santuarios de la naturaleza, y que: "la SMA, durante el procedimiento de fiscalización, que terminó en la Resolución Recurrida, debió consultar al Ministerio del Medio Ambiente -el que debe contar con el acuerdo del Consejo de Monumentos Nacionales- sobre los límites del Santuario, cosa que no ocurrió. La ausencia de este trámite vicia la Resolución Recurrida, por lo que este Tribunal la anulará, por haber sido pasada sin la consulta de rigor a la autoridad competente, única autorizada para definir si el Predio se encontraba o no dentro del Santuario".

Hay dos aseveraciones en el considerando:

- La primera, que el Ministerio define y modifica los límites de los santuarios de la naturaleza. 
- La segunda, que ese Ministerio era quien debía informar a la Superintendencia sobre esos límites, ya que era la única autoridad competente para definir si el predio se encontraba dentro de los límites del Santuario.

En relación a la primera afirmación, como ya se dijo, el Santuario de la Naturaleza Carlos Anwandter fue creado por el Decreto Supremo No 2734 del Ministerio de Educación del año 1981 en el cual se fijaron sus límites.

En consecuencia, en estos autos la consulta a que se refiere el Tribunal no dice relación con la creación o modificación de límites del Santuario, sino con la definición de si un predio se encuentra o no dentro de los límites contenidos en el Decreto Supremo citado, en otros términos, radicaba en la interpretación práctica en relación a un lugar geográfico determinado de los límites fijados en el Decreto Supremo.

Al Ministerio del Medio Ambiente, conforme a lo establecido en el artículo 70 letra b) de la Ley $\mathrm{N}^{\circ} 19.300$, en lo que dice relación con la materia en análisis, le corresponde "Proponer las políticas, planes, programas, normas y supervigilar el Sistema Nacional de Áreas Protegidas del Estado, que incluye parques y reservas marinas, así como los santuarios de la naturaleza, y supervisar el manejo de las áreas protegidas de propiedad privada”.

Esta potestad le fue conferida por el artículo $1^{\circ} \mathrm{N}^{\circ} 63$ de la Ley $\mathrm{N}^{\circ} 20.417$, la que modificó también en su artículo $4^{\circ}$ el artículo 31 de la Ley $\mathrm{N}^{\circ} 17.288$, que entregó la custodia de los santuarios de la naturaleza a este Ministerio.

Interpretando en forma armónica las normas citadas la custodia que se le entrega es la relativa al ejercicio de las competencias aludidas en la letra b) del artículo 70 ya transcrita.

Como ya se dijo, la misma Ley $\mathrm{N}^{\circ} 20.417$ modificó el artículo 34 de la Ley $\mathrm{N}^{\circ} 19.300$, entregando al Servicio de Biodiversidad y Áreas Protegidas la administración y supervisión del Sistema Nacional de Áreas Protegidas, entre los cuales se encuentran los santuarios de la naturaleza.

El administrador y supervisor de los santuarios, es quien por ley debe otorgar los permisos para ejecutar obras, naturalmente que para acceder o denegar la realización de ellas, tiene que confrontar los límites fijados en el Decreto Supremo que crea el Santuario con el lugar de emplazamiento físico en que estas se realizarán y determinar si ellas se encuentran o no dentro de los límites establecidos en el Decreto Supremo que lo establece, pero ello no significa, como ya se explicitó que esté creando o modificando el límite de un santuario.

Décimo: Que en este entendimiento y acorde con lo razonado en el considerando octavo, el Consejo de Monumentos Nacionales era quien tenía que informar a la Superintendencia si las obras se ejecutaron o no dentro de los límites del Santuario de la Naturaleza Carlos Anwandter.

Undécimo: Que, sin perjuicio de lo expuesto, el Ministerio del Medio Ambiente al requerimiento de información solicitada por la Superintendencia delegó la emisión 
de la misma al Consejo de Monumentos Nacionales, a quien legalmente correspondía efectuarla.

Duodécimo: Que por lo razonado no se configura el vicio atribuido por los sentenciadores en la emisión del informe respecto de los límites del Santuario de la Naturaleza Carlos Anwandter.

Décimotercero: Que por último, en relación a este punto, del tenor de los considerandos $87^{\circ}$ y $92^{\circ}$ del fallo recurrido, los sentenciadores concluyen en forma categórica que el Predio Tres Bocas se encuentra dentro del Santuario de la Naturaleza Carlos Anwandter.

Décimocuarto: Que en cuanto a la falta de fundamentación por parte de la Superintendencia sobre el carácter insular del lugar en que se encuentra el predio, en cuanto no se justificaría la conclusión que este se encuentra en una isla, el fallo recurrido concluye en forma categórica en el considerando $87^{\circ}$ que: "la discusión sobre la naturaleza geográfica del terreno donde se emplaza el Predio es inconducente a la resolución de la presente causa”.

Décimoquinto: Que el artículo 13 inciso segundo de la Ley $\mathrm{N}^{\circ} 19.880$ dispone que: "El vicio de procedimiento o de forma solo afecta la validez del acto administrativo cuando recae en algún requisito esencial del mismo, sea por su naturaleza o por mandato del ordenamiento jurídico y genera perjuicio al interesado”.

Décimosexto: Que a propósito del principio de conservación del acto administrativo que refleja la disposición legal precedentemente citada, la jurisprudencia de esta Corte ha sostenido en forma reiterada que revistiendo la nulidad el carácter de remedio excepcional frente a la ilegalidad de un acto administrativo, ella solo será procedente si el vicio es grave y esencial. Subyacen a este principio de conservación otros principios generales del Derecho como la confianza legítima que el acto genera, así como la buena fe de los terceros, el respeto a los derechos adquiridos y la seguridad jurídica. Efectivamente, no cualquier irregularidad o defecto justifica la declaración de nulidad, sino cuando dicha anomalía conculque las garantías de los administrados. (CS roles 5815-2011; 57-2011; 274-2010; 3078-2013).

Décimoséptimo: Que en la doctrina del derecho procesal, el denominado "principio de trascendencia" supone en célebres palabras de Couture, que "las nulidades no tienen por finalidad satisfacer pruritos formales, sino enmendar los perjuicios efectivos que pudieran surgir de la desviación de los métodos de debate cada vez que esta desviación suponga restricción de las garantías a que tienen derecho los litigantes'. Tal como apunta Alsina, la ineficacia que se sigue de la nulidad debe tener una finalidad práctica, no procediendo la nulidad por la nulidad misma”. (Gorigoitía Abbott, Felipe, "El perjuicio reparable solo por la declaración de nulidad como estándar de invalidez de las 
actuaciones procesales civiles", Rev. de Derecho de la Pontifica Universidad Católica de Valparaíso” XL, Valparaíso, Chile, 2013, 1 Semestre, pág. 579).

Decimooctavo: Que a juicio de estos sentenciadores, en el evento de configurarse este vicio de procedimiento en cuya virtud la sentencia anula el procedimiento de fiscalización llevado a cabo por la recurrente, este no tendría el carácter de grave y esencial, razón por la cual no acarrean la nulidad del procedimiento y de la Resolución $\mathrm{N}^{\circ} 98$ que puso término al mismo.

Decimonoveno: Que, en efecto, en estos autos no se ha demostrado que el antedicho vicio haya causado un perjuicio concreto relativo al interés jurídico del reclamante de autos que haya producido una afectación de su derecho a defensa respecto de la Resolución No 98 de la Superintendencia del Medio Ambiente.

Vigésimo: Que como es sabido, la regla general, por aplicación del principio de trascendencia, es que no hay nulidad sin perjuicio, concepto consagrado en el artículo 13 inciso segundo de la Ley $\mathrm{N}^{\circ} 19.880$, disposición que se denuncia como infringida por el recurrente.

Vigésimo Primero: Que en razón de lo expuesto no cabe sino concluir, que los sentenciadores al fallar como lo hicieron incurrieron en errores de derecho al disponer la nulidad del procedimiento de fiscalización ambiental y de la Resolución $\mathrm{N}^{\circ}$ 98, toda vez, que por una parte infringieron el artículo 13 de la Ley $N^{\circ} 19.880$ al establecer que constituye un vicio la omisión de informe del Ministerio del Medio Ambiente sobre los límites del Santuario de la Naturaleza Carlos Anwandter, en circunstancias que ello no es así y, por otra parte, la falta de fundamentación del carácter insular del predio no tuvo la entidad para causar la nulidad de la aludida resolución, sin que se probara que su ocurrencia, de existir, hubiera causado un perjuicio al interesado.

Vigésimo Segundo: Que estos errores influyeron sustancialmente en lo dispositivo del fallo, pues indujeron a anular la Resolución $\mathrm{N}^{\circ} 98$ que requirió el ingreso al Sistema de Evaluación Ambiental del Proyecto Loteo Riberas de La Dehesa, motivo por el cual se invalidará la sentencia recurrida.

De conformidad con lo dispuesto en los artículos 764, 767, 785 y 805 del Código de Procedimiento Civil y 26 de la Ley N² 20.600 se acoge el recurso de casación en el fondo interpuesto por la Superintendencia del Medio Ambiente a fs. 464 en contra de la sentencia de treinta de mayo de dos mil catorce del Tercer Tribunal Ambiental, escrita a fs. 385 y siguientes, la que, por consiguiente, es nula y se reemplaza por la que se dicta a continuación.

Regístrese y devuélvase con sus agregados.

Redacción de la Ministro señora María Eugenia Sandoval.

Rol No 16.706-2014.

Pronunciado por la Tercera Sala de esta Corte Suprema integrada por los Ministros Sr. Rubén Ballesteros C., Sr. Pedro Pierry A., Sra. Rosa Egnem S., Sra. María Eugenia 
Sandoval G., y Sr. Juan Eduardo Fuentes B. No firma, no obstante haber concurrido a la vista y al acuerdo de la causa, el Ministro señor Ballesteros por haber cesado en sus funciones. Santiago, 10 de diciembre de 2014.

Autoriza la Ministra de Fe de la Excma. Corte Suprema.

En Santiago, a diez de diciembre de dos mil catorce, notifiqué en Secretaría por el Estado Diario la resolución precedente.

\section{Comentario}

La jurisprudencia que se comenta corresponde a una decisión importante para un caso que surge de una denuncia ciudadana y que reveló que, a 33 años de la creación del Santuario de la Naturaleza del río Cruces y Chorocamayo (por el D.S N 2.734 de 3 de junio de 1981, del Ministerio de Educación Pública), aún no se había elaborado por el organismo competente la cartografía oficial de esta área protegida, evidenciando nuevamente la existencia de confusiones acerca del contenido y alcance de las competencias de los órganos públicos que inciden en su tutela. Además, esta sentencia supone un avance para la comprensión de la nueva institucionalidad ambiental, ya que, al no cuestionar el ejercicio que la Superintendencia del Medio Ambiente realizó de su atribución, la Corte confirma la facultad de esta para requerir, previo informe del Servicio de Evaluación Ambiental, mediante resolución fundada y bajo apercibimiento de sanción, a los titulares de proyectos o actividades que debieron someterse al sistema de evaluación de impacto ambiental (SEIA) y que no cuenten con una resolución de calificación ambiental (RCA), para que sometan a dicho sistema; y a los titulares de proyectos que ya cuenten con una RCA, para que sometan al SEIA las modificaciones o ampliaciones de sus proyectos o actividades que requieran de una nueva RCA (artículo 3, letras i) e j) en relación con el artículo 35 letra b), Ley Orgánica de la Superintendencia del Medio Ambiente, establecida en el artículo segundo de la Ley 20.417) ${ }^{1}$.

La controversia jurídica que surge de la sentencia anulada del Tribunal Ambiental recaía sobre el alcance y contenido de las potestades públicas del organismo del Estado. Para la Corte, el Tribunal Ambiental no habría considerado correctamente las modificaciones introducidas por la Ley 20.417, siendo jurídicamente correcto que el Ministerio del Medio Ambiente, frente al requerimiento de la información solicitada por la SMA,

${ }^{1}$ El ejercicio de dicha facultad de la Superintendencia del Medio Ambiente había sido cuestionada por el Segundo Tribunal Ambiental en su sentencia de 22 de mayo de 2014, pronunciada en causa Rol No R-152013, en el que se pronunció sobre la reclamación de Inmobiliaria Alameda S.A. en contra de la resolución de la SMA que requirió el ingreso del proyecto inmobiliario "Santiago Downtown" al SEIA. En este caso, el Tribunal Ambiental limitó extraordinariamente las facultades de la SMA, al señalar que la comprobación que realiza esta para determinar si un proyecto debe o no ingresar al SEIA debe realizarse en el contexto de un procedimiento administrativo sancionador, toda vez que para acreditar la concurrencia de un incumplimiento a la legislación ambiental debe discutirse si existe o no una obligación de ingresar el proyecto al SEIA, permitiéndose al titular la posibilidad de efectuar descargos, de acuerdo con el principio de contradictoriedad consagrado en el artículo 10 de la Ley 19.880 de Bases del Procedimiento Administrativo (LBPA). 
delegara la emisión de la misma al Consejo de Monumentos Nacionales, a quien legalmente correspondía efectuarla. Razón por la que no se configura el vicio atribuido por el Tribunal en la emisión del oficio respecto de los límites del Santuario.

Así, luego de realizar una interpretación armónica de las modificaciones que introduce la Ley 20.417, la Corte concluye que la emisión del oficio respecto de los límites del Santuario no corresponden al ejercicio de las facultades del custodio de este, radicadas en el Ministerio del Medio Ambiente, sino a su administrador y supervisor, quien está facultado para interpretar prácticamente si una determinada área geográfica se ubica dentro de los límites del Santuario fijados en el Decreto que lo creaba. Esto no significaba, como suponía el Tribunal Ambiental, que se esté creando o modificando los límites del Santuario. Ahora bien, de acuerdo con la redacción actual de la ley, la administración y supervisión recae en el Servicio de Biodiversidad y Áreas Protegidas, que aún no se ha creado. Sin embargo, esta situación no significa que la función que a este le compete no deba ser ejercida por otro órgano de la administración, toda vez que de acuerdo al principio de continuidad de la función pública, la potestad de autorizar las obras que se realizan en los santuarios de la naturaleza se encuentra radicada hoy en el Consejo de Monumentos Nacionales.

De esta forma, este fallo supone un avance en la comprensión de la institucionalidad encargada de garantizar que se cumpla la función pública tras el objetivo de conservación de esta área silvestre protegida y humedal de importancia internacional. En efecto, la decisión de la Corte Suprema es significativa respecto del fenómeno ventilado: el desarrollo de proyectos urbanísticos en detrimento de nuestros humedales, bienes comunes y patrimonio natural. Dicho problema, quizás por su visibilidad, se ha observado fundamentalmente dentro del perímetro urbano. Sin embargo, este caso nos enfrenta a una nueva realidad, la urbanización y expansión de nuestra ciudad hacia el área del humedal del río Cruces y sus ríos tributarios, siendo el SEIA el único instrumento con el que actualmente contamos para poder definir y ordenar con carácter vinculante las actividades que se pretendan realizar en su interior.

Por lo demás, se trata de una sentencia que incide en uno de los aspectos más problemáticos que quedaron en evidencia luego del desastre ecológico que significó la contaminación del Santuario, tras la instalación y funcionamiento de la planta de la empresa Celulosa Arauco y Constitución S.A durante el 2004: la poca claridad acerca de las atribuciones y competencias de los órganos públicos que inciden en la gestión del Santuario. Hoy queda despejado que es el Consejo de Monumentos Nacionales quien tiene a cargo la administración del Santuario y debe autorizar previamente trabajos de construcción, excavación o el desarrollo de cualquier actividad que pudiera alterar su estado natural, hasta que se cree el Servicio de Biodiversidad y Áreas Protegidas. Por consiguiente, es el Ministerio del Medio Ambiente quien tiene a su cargo la custodia del Santuario, lo que implica proponer políticas, planes, programas, normas y supervigilar el Sistema Nacional de Áreas Protegidas del Estado, que incluye los santuarios de la naturaleza. Este fallo nos ofrece un diagnóstico de la situación institucional, mejorando la comprensión de las atribuciones que corresponden a los diversos organismos públicos en el ámbito de la gestión del humedal, que permitan la coordinación de estos 
para prevenir futuros desastres. Evidentemente que en este sentido el comentado fallo resulta ser un insumo de enorme trascendencia para el diseño y consolidación de una comprensión común de las instituciones y organizaciones ciudadanas comprometidas en la conservación del Santuario. 